\title{
LETRAMENTO \\ RACIAL E \\ TÉCNICAS \\ DE SI ${ }^{1}$
}

\section{LITERACIDAD RACIAL Y TÉCNICAS DE SÍ}

\section{RACIAL LITERACY AND TECHNIQUES OF THE SELF}

Renata Trindade Severo*

Instituto Federal do Rio Grande do Sul

\begin{abstract}
RESUMO: No dispositivo da racialidade, encena-se a agonística entre o poder racista e a resistência a ele. Este artigo retoma o Movimento da Negritude e suas repercussões para traçar as transformações pelas quais o dispositivo tem passado até chegar às práticas de letramento racial que produzem sujeitos críticos à naturalização da racialização. Nesse percurso, aborda de forma introdutória o conceito de branquitude e os Estudos Críticos da Branquitude. Além disso, relaciona o letramento racial ao conceito foucaultiano de técnicas de si a fim de evidenciar tanto as características de prática e exercício compartilhadas por ambos quanto os efeitos de subjetivação produzidos. Ao longo do artigo, conceitos de Émile Benveniste são empregados para ilustrar a maneira como a intersubjetividade tem papel fundamental na produção da subjetividade.

PALAVRAS-CHAVE: Enunciação. Branquitude. Letramento racial. Racismo. Técnicas de si.
\end{abstract}

RESUMEN: En el dispositivo de la racialidad, se pone en escena el agonismo entre el poder racista y la resistencia a ese poder. En este artículo se retoma el Movimiento de la Negritud y sus repercusiones para apuntar las transformaciones por las cuales ha pasado el dispositivo hasta llegar las prácticas de literacidad racial que producen sujetos críticos con respecto a la naturalización de la racialización. En ese recorrido, se abordan de forma introductoria el concepto de blanquitud y los Estudios Críticos de la Blanquitud. Además, se relaciona la noción de literacidad racial al concepto foucaultiano de técnicas de sí a fin de poner de manifiesto tanto las características de práctica y ejercicio compartidas por ambos como los efectos de subjetivación producidos. A lo largo del artículo, se emplean conceptos de Émile Benveniste para ilustrar cómo la intersubjetividad tiene un papel fundamental en la producción de la subjetividad.

PALABRAS CLAVE: Enunciación. Blanquitud. Alfabetización racial. Racismo. Técnicas de sí.PALABRAS CLAVE: Enunciación.

ABSTRACT: In the dispositif of raciality, the agonistic between racist power and the resistance to it is enacted. This article takes up the Movement of Negritude and its repercussions to trace the transformations this dispositif has undergone until reaching the racial

${ }^{1}$ O presente trabalho foi realizado com apoio do Instituto Federal do Rio Grande do Sul, Processo no 23368.002516/2019-43, por meio do afastamento para estudos para realização de estágio de pós-doutoramento no PPGLin/UFSC. 
literacy practices that produce subjects critical to the naturalization of racialization. Along the way, it introduces the concept of whiteness and the Critical Whiteness Studies in an introductory way. Furthermore, it relates racial literacy to Foucault's concept of techniques of the self in order to highlight both the characteristics of practice and exercise shared by both and the effects of subjectivation produced. Throughout the article, concepts from Emile Benveniste's thought are used to illustrate how intersubjectivity plays a fundamental role in subjectivity production.

KEYWORDS: Enunciation. Whiteness. Racial literacy. Racism. Techniques of the self.

\section{INTRODUÇÃO}

"Como se vê, esse papo de democracia racial, atingida mediante a miscigenação, não passa de um mito muito bem bolado"

(GONZALEZ, 2018 [1981b], p. 108)

A afirmação de Lélia Gonzalez que serve de epígrafe a este texto, publicada na terceira edição do Jornal Mulherio (1981), é uma das tantas formas como a intelectual brasileira articulou o que procurava deixar explícito em todo seu trabalho: a democracia racial brasileira era uma mentira. Naquele período, os anos 1980, denunciar o mito da democracia racial e evidenciar o racismo como estruturante da sociedade brasileira estavam entre os objetivos chave do Movimento Negro Unificado, que Lélia ajudou a fundar e no qual era militante (RATTS; RIOS, 2010). Quase trinta anos antes, os trabalhos desenvolvidos no contexto do Projeto Unesco ${ }^{2}$, no início dos anos 50 do século passado, já "descobriam" que a democracia racial brasileira não passava de uma fantasia - o que surpreendeu tanto os sociólogos brancos envolvidos no projeto quanto a própria UNESCO (Organização das Nações Unidas para a Educação, a Ciência e a Cultura), que havia escolhido o Brasil para o desenvolvimento dessas pesquisas justamente na tentativa de compreender e divulgar a receita para a aparente harmonia racial brasileira (MAIO, 1999). Quase três décadas separam a afirmação de Lélia e a publicação dos resultados das pesquisas do Projeto Unesco, outras quatro a separam dos dias atuais. No entanto, ainda há quem afirme que não existe racismo no Brasil, a exemplo do vice-presidente da República (HAMILTON..., 2020). No Brasil, produzir racismo e negá-lo são movimentos complementares e não antagonistas, conforme veremos.

O antropólogo austríaco Andreas Hofbauer (2007) vê no Projeto Unesco o surgimento do tema "discriminação racial" em trabalhos da sociologia brasileira que negam, assim, o mito da democracia racial; no entanto, é apenas em pesquisas do final dos anos 1990 que o autor identifica o desenvolvimento de um olhar para esse mito no sentido antropológico do termo: a origem de uma narrativa que produz sentido. Segundo Hofbauer, os trabalhos de Schwarcz (1998), Da Matta (1997) e Fry (1995/1996) questionariam, dentre outros pontos, por que, no Brasil, as pessoas preferem evitar o conflito e negociar suas identidades raciais. O que Hofbauer não menciona $^{3}$ são, por exemplo, os diversos trabalhos de Gonzalez $\left(1979,1980,1981^{a}\right.$, 1981b, 1981c, 1985) em que a autora, já nos 70 e 80, denuncia o mito e o analisa a partir de diferentes perspectivas que poderiam, inclusive, responder ao questionamento dos autores mencionados por Hofbauer (2007). Ao analisar o mito a partir do "duplo fenômeno do racismo e do sexismo" Gonzalez (1980, p.191) já propunha um percurso analítico que nomeava o mito e oferecia uma explicação para sua manutenção ${ }^{4}$.

Mais recentemente, Liv Sovik (2005) oferece uma perspectiva que pode contribuir com essa reflexão ao colocar em relevo dois aspectos do mito da democracia racial - a mestiçagem e o lugar do branco na equação racial:

\footnotetext{
2 "Nos anos de 1951 e 1952, a Organização das Nações Unidas para a Educação, Ciência e Cultura (Unesco) patrocinou uma série de pesquisas sobre as relações raciais no Brasil.” (MAIO, 1999, p. 141). Para saber mais sobre o Projeto Unesco, recomendo a leitura de Maio (1999) e Hofbauer (2007).

${ }^{3}$ Por limitação de espaço, não discutiremos aqui o apagamento do pensamento de Gonzalez nas discussões sobre raça. Recomendamos a leitura de Cardoso (2014) para um aprofundamento nesse importante debate.

${ }^{4}$ Não será possível, neste espaço, abordarmos os trabalhos de Gonzalez citados. Para sua análise sobre a ampla aceitação do mito da democracia racial, ver "Racismo e sexismo na cultura brasileira" (GONZALEZ, 2018 [1980]).
} 
Em um país mestiço, os brancos são irrelevantes, pois a questão é de misturar-se, deixar-se misturar, reconhecerse como produto da mistura, o que, paradoxalmente, sempre é possível sem deixar de ser branco. Pois ser branco no Brasil é ter a pele relativamente clara, funcionando como uma espécie de senha visual e silenciosa para entrar em lugares de acesso restrito. (SOVIK, 2005, p. 171)

Ou seja, uma das explicações para a persistente manutenção do mito da democracia racial, apesar dos diversos estudos que o desmentem, é que tal mito permite, paradoxalmente, que pessoas brancas acessem os privilégios destinados a elas pelo sistema racista sem que tenham que se preocupar em justificar-se frente ao racismo. No entanto, conforme sinaliza Sovik, no início do século XXI, o branco passa a ser percebido como problema na equação racial, já que "[...] a militância cultural e política negra e as estatísticas oficiais informam que o Brasil não é só um país de mestiços, mas de pretos e pardos, de um lado, e de brancos, do outro." (SOVIK, 2005, p. 171). Sovik continua e sugere um papel para as pessoas brancas no Brasil:

Nesse sentido, cabe aos brancos uma renovada reflexão sobre seu lugar na sociedade brasileira, para preceder a uma ação também de brancos contra o racismo. [...] [É] necessário encontrar não só formas concretas de combater juntos o racismo, mas de tirar o peso do argumento que, em um país mestiço, está tudo (relativamente) bem. (SOVIK, 2005, p. 171)

Ao mesmo tempo em que assume a mestiçagem como uma realidade brasileira, a autora nega a democracia racial, uma vez que, mesmo em um país que ela considera mestiço - mas onde ainda há brancos, pardos e pretos -, os brancos permanecem em lugar de privilégio em relação aos não brancos. A percepção de que brancos têm um papel a ser desempenhado no combate ao racismo está no centro do que hoje chamamos Estudos Críticos da Branquitude. Dentro desse campo, a pesquisadora afro-americana France Winddance Twine (TWINE, 2004 apud TWINE; STEINBUGLER, 2006) cunhou o nome Racial Literacy para se referir a um conjunto de práticas que permite que pessoas racializadas tanto como brancas quanto como não brancas passem a perceber a racialização e suas consequências na sociedade.

Schucman (2012, p.188), ao traduzir Racial Literacy, apesar de propor a expressão "letramento racial crítico", emprega uma tradução mais próxima à original em inglês: letramento racial. Em sua pesquisa de doutorado, em que entrevistou sujeitos brancos sobre sua branquitude, a pesquisadora identificou práticas que fizeram com que uma parte de seus entrevistados, desenvolvesse letramento racial, alterando sua percepção das relações sociais mediadas por raça.

Da crença em uma democracia racial à percepção do branco como fator importante na problemática racista, um longo caminho foi construído pelos movimentos negros e pelas pesquisas que se produziram nesse campo. Uma das formas como se pode efetuar um recorte na produção dessa transformação é acompanhar as linhas de proveniência (FOUCAULT, 1998) que se desenham a partir do que ficou conhecido como Movimento da Negritude. A partir dos discursos produzidos por esse movimento, estabelece-se um regime de verdade que tensiona a produção dos sujeitos racializados. Manifestações contemporâneas desses discursos podem ser localizadas nos Estudos Críticos da Branquitude e no conceito de letramento racial, por exemplo. Neste artigo, proponho que o letramento racial constitui um conjunto de técnicas de si por meio do qual indivíduos brancos podem dissociar ${ }^{5}$ brancura - a cor branca da pele e os traços característicos das pessoas brancas - de branquitude - o pensamento segundo o qual pessoas brancas são superiores a pessoas não brancas, ambos processos internos ao dispositivo da racialidade (CARNEIRO, 2005).

Inicialmente, caracterizarei parcialmente o dispositivo da racialidade partindo do que Sueli Carneiro (2005) propõe em diálogo com o conceito de dispositivo da sexualidade de Michel Foucault (2006). Além da noção de dispositivo, outros elementos do universo analítico foucaultiano serão mobilizados: abordarei a tensão entre os regimes de verdade que, no interior do dispositivo, concorrem na produção de sujeitos. Trata-se, no caso do dispositivo da racialidade, do regime de verdade racista - que configura o poder - e dos regimes de verdade que se constroem a partir dos discursos articulados pela Negritude (DOMINGUES, 2005; MOORE, 2010; CÉSAIRE, 2010; MBEMBE, 2018) - que configuram a resistência a esse poder.

\footnotetext{
${ }^{5}$ A percepção de que o letramento racial permite que sujeitos brancos consigam dissociar brancura e branquitude é de Schucman (2012), que verifica, ao final de sua tese de doutorado, que uma pequena parte de seus entrevistados é capaz de operar essa dissociação. Neste artigo, proponho que o letramento racial pode ser visto como técnica de si, no sentido foucaultiano.
} 
Abordarei os discursos que produzem tensionamentos com o regime de verdade racista. Partirei da descrição de Mbembe (2018) da "consciência ocidental do negro" e da "consciência negra do negro" para ilustrar dois regimes de verdade antagônicos no dispositivo da racialidade. Aproveito a relação estabelecida pelo filósofo camaronês entre "consciência negra do negro" e Negritude para, ao deter-me brevemente nesse Movimento, traçar as linhas de proveniência que partem dele e chegam aos Estudos Críticos da Branquitude e às práticas de letramento racial. Pensando, com Veyne, que o discurso atualiza o dispositivo - "o próprio discurso é imanente ao dispositivo que se modela a partir dele [...] e que o encarna na sociedade" (VEYNE, 2011, p. 54) -, procurarei mostrar algumas formas como os discursos da Negritude e dos Estudos Críticos da Branquitude produzem diferentes efeitos nos processos de produção de sujeitos, efeitos que podem ser observados no exercício das práticas de si do letramento racial e na subjetivação resultante. Em momentos específicos, recorrerei ao pensamento de Émile Benveniste $(2005,2006)$ para ilustrar enunciativamente a produção dos sujeitos da Negritude por meio de gestos de autodefinição.

\section{O DISPOSITIVO DA RACIALIDADE}

Sueli Carneiro (2005) baseia-se na descrição que Foucault oferece de dispositivo da sexualidade para elaborar o conceito de dispositivo da racialidade. Segundo a filósofa,

[...] da perspectiva foucaultiana, entendemos as relações raciais no Brasil como um domínio que produz e articula saberes, poderes e modos de subjetivação, conformando um dispositivo de racialidade. Consideramos que tal como ele afirma para o caso da sexualidade, se a racialidade se coloca como um domínio a conhecer, é porque relações de poder a "instituíram como objeto possível; em troca, se o poder pode tomá-la como alvo foi porque se tornou possível investir sobre ela através de técnicas de saber e de procedimentos discursivos." (Foucault, 1988, p. 93). Preliminarmente, a racialidade é aqui compreendida como uma noção relacional que corresponde a uma dimensão social, que emerge da interação de grupos racialmente demarcados sob [sic] os quais pesam concepções histórica e culturalmente construídas acerca da diversidade humana. Disso decorre que ser branco e ser negro são consideradas polaridades que encerram, respectivamente, valores culturais, privilégios e prejuízos decorrentes do pertencimento a cada um dos pólos das racialidades. (CARNEIRO, 2005, p. 34)

O conceito biológico de raça, aplicado ao ser humano em prol de um projeto de dominação do capitalismo branco patriarcal ocidental (GROSFOGUEL, 2016; MUNANGA, 2004), tem papel importante nesse dispositivo. Ainda que a afirmação da existência de raças biológicas humanas não seja mais aceita, raça enquanto construto social continua operando no dispositivo que a produz e sustenta (MUNANGA, 2004). A apropriação do conceito biológico de raça e seu emprego em relação a seres humanos é produto do dispositivo da racialidade, assim como o sexo é produzido pelo dispositivo da sexualidade (FOUCAULT, 1977, 2006), em outras palavras, embora a ideia de raça fundamente o racismo, ela não o antecede pois é produzida por ele -uma vez que os processos de opressão de povos negros e indígenas, por exemplo, ou seja, processos racistas, já existiam antes da articulação do conceito "raça", produzido pelo discurso científico do século XIX. O racismo se confunde com o próprio dispositivo da racialidade, pois substantiva o poder exercido no dispositivo. Ele é complexo, produz e é produzido por discursos pseudo-científicos e científicos, religiosos, nacionalistas etc.; estrutura grande parte das sociedades contemporâneas, impregna suas instituições e produz subjetividades.

Poder, aqui, é o poder segundo Foucault: não se trata de algo que se tem ou que se tome, mas algo que se exerce. Poder e resistência são duas forças em relação que produzem efeitos sobre os processos de subjetivação. Em O sujeito e o poder (FOUCAULT, 1995), o filósofo francês sugere, inclusive, que se estude o poder a partir das resistências: "[...] usar esta resistência como um catalisador químico de modo a esclarecer as relações de poder [...] Mais do que analisar o poder do ponto de vista de sua racionalidade interna, ela consiste em analisar as relações de poder através do antagonismo das estratégias” (FOUCAULT, 1995, p. 234). Poder e resistência são forças que agem no interior do dispositivo - "[...] um conjunto decididamente heterogêneo que engloba discursos, instituições, organizações arquitetônicas, decisões regulamentares, leis, medidas administrativas, enunciados científicos, proposições filosóficas, morais e filantrópicas. Em suma, o dito e o não dito são os elementos do dispositivo” (FOUCAULT, 1998, p. 244). 
Assim, o dispositivo da racialidade (CARNEIRO, 2005) é produtor de sujeitos racializados e a resistência que opera no interior do dispositivo cria nuances nessa subjetivação. Se o racismo constitui o sujeito negro brutalizado e o sujeito da branquitude ${ }^{6}$, a Negritude e seus desdobramentos produzem o sujeito negro humanizado e o sujeito da branquitude crítica ${ }^{7}$.

Em seu processo de "[...] criar uma história dos diferentes modos pelos quais, em nossa cultura, os seres humanos tornaram-se sujeitos" (FOUCAULT, 1995, p. 231), Foucault estuda a objetivação do sujeito no que ele nomeou "práticas divisoras": "[o] sujeito é dividido no seu interior e em relação aos outros. Este processo objetiva” (FOUCAULT, 1995, p. 231). Os exemplos mencionados por Foucault ${ }^{8}$ ilustram o funcionamento de tais práticas: criam-se binômios, um polo positivo e um negativo. Tal funcionamento se repete no dispositivo racial: enquanto os sujeitos racializados como não brancos se produzem como o lado objetificado, brutalizado do binômio humano/não humano, ao sujeito branco são reservados os atributos de tudo que é bom, belo e íntegro. Em uma relação de projeção (GONZALEZ, 1980; BENTO, 2014; KILOMBA, 2019), os crimes do colonizador são atribuídos aos colonizados ${ }^{9}$ : as violências simbólica e física - que se materializam geográfica, econômica e socialmente, por exemplo - perpetradas historicamente contra os corpos não brancos são vistas como inerentes a esses corpos.

A proveniência (FOUCAULT, 1998) do dispositivo da racialidade no Brasil pode ser retraçada a partir do início dos processos de invasão das Américas pelos europeus no final do século XV e se entrelaça com as formas de dominação colonial praticadas na Ásia, na Oceania e, principalmente, na África. Grosfoguel (2016) situa na controvérsia de Valladolid (1551), quando a Igreja Católica procurava determinar se os povos encontrados nas Américas eram humanos ou não - se tinham alma ou não - o primeiro debate racista documentado. O resultado do julgamento levou a coroa espanhola a mudar o regime de opressão sobre os povos indígenas - substituindo a escravização indígena pelo regime de encomiendas e espalhando-o pela América invadida pela Espanha - e, ao mesmo tempo, catalisou os processos de captura e tráfico de escravizados do continente africano para o novo mundo.

Diferentes autores situam a origem e o desenvolvimento do racismo em pontos diversos da história. Para o Foucault (1993) de Em defesa da sociedade, por exemplo, o racismo se estrutura como tal no século XIX; já para Moore (2010, 2012), o racismo remonta à Antiguidade, enquanto para Grosfoguel (2016), pode ser localizado na virada do século XV para o XVI. Coerentemente, o próprio conceito de racismo varia, mantendo, no entanto, algo em comum: aquilo que Foucault chamou de "prática divisora", que aqui podemos resumir como a marcação do outro (povo) como diferente e a hierarquização dessa diferença como justificativa para a dominação do um sobre o outro.

O dispositivo da racialidade vem se constituindo, através dos séculos, por um emaranhado de discursos: religiosos, biológicos, antropológicos etc. Estados foram criados e estruturados sobre a ideia de que há raças, de que há hierarquia entre raças e de que, portanto, é válido que apenas uma dessas raças, a que se encontra no topo da hierarquia, exerça poder sobre as outras. O Brasil é um desses Estados: nosso país constituiu-se como nação no dispositivo da racialidade; o racismo já dominava o território desde o início da colonização - já que não há colonização sem racismo - e o racismo está nos pilares de todas as estruturas brasileiras: as instituições jurídicas e de governo, a distribuição de terras, o acesso à educação e a todos os direitos civis - mesmo a língua e a literatura - foram desde o princípio marcadas explicitamente (LUCCHESI, 2011) pelo racismo contra povos e pessoas negras e indígenas.

No entanto, o racismo configura um poder e, como tal, encontra resistência (FOUCAULT, 2006): desde que há opressão racista, há povos racializados que resistem. Muitos cortes podem ser feitos para se individuar as formas de resistência que se organizaram ao

${ }^{6} \mathrm{O}$ discurso racista não nomeia a branquitude ou seus sujeitos: esse gesto é produzido a partir dos discursos da Negritude; tal gesto nomeia o sujeito branco e, assim, a branquitude. Frankenberg (2004) aprofunda a questão da marcação ou não da branquitude: "a construção e a marcação da branquidade precisam ser esclarecidas antes que possamos começar a compreender sua não marcação ocasional, parcial e temporária no fim do século XX.” (FRANKENBERG, 2004, p. 309, grifo da autora). Este artigo, por questões de espaço, ater-se-á a pensar o aspecto de neutralidade atribuído à branquitude quando essa não é nomeada ou marcada.

\footnotetext{
${ }^{7}$ Para um aprofundamento sobre o sujeito da branquitude crítica, em contraste com o sujeito da branquitude acrítica, sugiro a leitura de Cardoso (2010). Neste artigo, me valho desse conceito apenas provisoriamente, uma vez que, como veremos, a ideia de letramento racial mobiliza questões que o conceito de branquitude crítica não dá conta.

8“[...] o louco e o são, o doente e o sadio, os criminosos e 'os bons meninos”" (FOUCAULT, 1995, p. 231).

${ }^{9}$ Colonização e racismo são dois elementos do mesmo dispositivo: colonizar só é possível em um regime de verdade racista (CÉSAIRE, 1950 apud MOORE, 2010).
} 
longo da história contra o poder racista. A seguir, abordarei a descrição que Mbembe (2018) oferece de dois textos antagônicos sobre raça - que eu tomo aqui como dois regimes de verdade que governam os processos de subjetivação no dispositivo racial: um, pelo exercício do poder e outro, pela resistência a ele.

\section{CONSCIÊNCIA OCIDENTAL DO NEGRO E CONSCIÊNCIA NEGRA DO NEGRO}

Em Crítica da razão negra, Achille Mbembe descreve o que nomeia "consciência ocidental do negro": um "[...] conjunto de vozes, enunciados e discursos, de saberes, comentários e disparates, cujo objeto são a coisa ou as pessoas 'de origem africana' e aquilo que se afirma ser seu nome e sua verdade [...]" (MBEMBE, 2018, p. 60) cuja "[...] função é, antes de mais nada, codificar as condições de surgimento e manifestação de um sujeito racial então chamado de negro [...] Chamemos esse primeiro texto de consciência ocidental do negro." (MBEMBE, 2018, p. 61, grifos do autor).

Mbembe também descreve um segundo texto - "[...] que se quer ao mesmo tempo gesto de autodefinição, modo de presença perante si mesmo, olhar interior e utopia crítica” (MBEMBE, 2018, p. 62). Em contraste com o primeiro, que, segundo o filósofo, por procurar responder à questão "Quem é esse?", "[...] se esforça por nomear uma realidade que lhe é exterior e que ele tende a situar em relação a um eu tomado como centro de toda e qualquer significação” (MBEMBE, 2018, p. 62), o segundo texto, a que Mbembe nomeia "consciência negra do negro" (MBEMBE, 2018, p. 65, grifos do autor), responde "[...] a uma outra categoria de interrogações colocadas à primeira pessoa do singular".

A "consciência ocidental do negro" é o texto em que o sujeito negro é produzido como um ele enquanto a "consciência negra do negro" é produzida por e produz um "eu". Podemos recuperar, aqui, a diferença entre "pessoa" e "não pessoa", que o linguista sírio Émile Benveniste (2005a [1956]) abordou a partir da língua e da linguagem a fim de evidenciarmos uma dimensão discursiva que extrapola, mas não nega aquela da língua. Rememoremos: ele é “[...] o membro não marcado da correlação de pessoa” que predica "o processo de não importa quem ou não importa o que [...]" (BENVENISTE, 2005a [1956], p. 282, grifos do autor) enquanto que eu é a categoria de pessoa que é instituída na intersubjetividade quando um indivíduo se apropria da língua e se enuncia em relação a um $t u$. É a polaridade e a complementariedade do par eu/tu, junto com a possibilidade de que $t u$, ao assumir a língua e enunciar-se, se torne eu que revela "o fundamento linguístico da subjetividade" (BENVENISTE, 2005b [1958], p. 287) que, para Benveniste, "não é mais que a emergência no ser de uma propriedade fundamental da linguagem" (BENVENISTE, 2005b [1958], p. 286). A passagem da terceira para a primeira pessoa é a diferença entre ser falado e falar: $e u$ indica aquele que fala, ele aquele de que se fala, o que está fora da interlocução. Mais tarde, retornarei a essa relação entre a condição linguístico-discursiva do ele e a autodefinição do sujeito negro.

A produção do segundo texto se dá, acredita Mbembe, no esforço de fundação de um arquivo cuja instauração "é indispensável para restituir os negros à sua história" (MBEMBE, 2018, p. 63). Tal arquivo reuniria "fragmentos, mobilizados para dar conta de uma experiência em si mesma fragmentada, a de um povo pontilhado, lutando para se definir não como um compósito disparatado, mas como uma comunidade [...]" (MBEMBE, 2018, p. 63). Esse esforço de produção de uma historiografia que crie laços comunitários, esse "ato de imaginação moral" (MBEMBE, 2018, p. 64), se traduz em "[...] gesto histórico por excelência [que] consiste, pois, em passar do estatuto de escravo ao de cidadão como os outros." (MBEMBE, 2018, p. 64, grifos do autor): de coisa a humano, de ele a eu. Dessa forma, algo que era impensável na proposta benvenisteana acontece: ele torna-se aquele que fala - o que, para Benveniste (2005a [1956] e 2005b [1958]) só poderia ser feito por tu, par na relação intersubjetiva com eu.

Os dois textos, apesar das "profundas discrepâncias", apresentam também “inegáveis solidariedades entre si” (MBEMBE, 2018, p. 65). O segundo, que é produzido para refutar o primeiro, “[...] traz consigo, em todo o seu conteúdo, os vestígios, as marcas, o murmúrio incessante e, por vezes, a surda cogência do primeiro e também sua miopia” (MBEMBE, 2018, p. 65). Para Mbembe, essa produção foi movida por "inúmeras correntes humanitárias e filantrópicas", foi criada por intelectuais que circulavam entre os continentes americano, europeu e africano, foi fruto das lutas abolicionistas e contra o capitalismo e se deu principalmente no século XIX e início do século XX. Dentre tais lutas e movimentos, a Negritude, referenciada juntamente ao nome de Aimé Césaire, é citada pelo filósofo como um movimento literário, feito por poetas. 
Aimé Césaire, no entanto, via a Negritude como algo muito além de uma corrente poética ou de um movimento literário. Para o escritor da Martinica, a Negritude teria nascido quando o povo do Haiti fundou a primeira república negra das Américas (MOORE, 2010) e viveria em todo gesto negro de autodefinição. Enquanto, para Mbembe, a Negritude é um dos elementos na produção do que ele chama consciência negra do negro, para Césaire, ela compreende todas as instâncias de produção dessa consciência.

\section{NEGRITUDE, BRANQUITUDE E ESTUDOS CRÍTICOS DA BRANQUITUDE}

Se o racismo produz raça, sujeitos racializados e uma hierarquia entre raças e, portanto, sujeitos, os discursos de resistência, especificamente aqueles produzidos no âmbito do movimento da Negritude ${ }^{10}$, não negam raça enquanto construto social, mas questionam a hierarquia, o modelo piramidal em que uma raça, no topo, oprime todas as outras, na base, em prol de um modelo horizontal, em que as diferenças não sejam apagadas, mas valorizadas (FANON, 2020; MOORE, 2010) ${ }^{11}$. Inicialmente ${ }^{12}$, não se tratava de dizer algo sobre o ser branco, mas de produzir discursos que recuperassem a história, as identidades e a humanidade do ser negro.

A Negritude produziu e produz novos regimes de verdade dentro do dispositivo da racialidade ao apresentar o sujeito negro como ser humano "como os outros" (MBEMBE, 2018). Se o dispositivo da racialidade produz o sujeito negro apenas com características negativas e o nomeia, mas produz o sujeito branco como a positividade sem, no entanto, nomeá-lo (ou melhor, guardando esse nome para momentos muito específicos ${ }^{13}$ ), a Negritude, ao revelar um dos segredos produzidos pelo racismo - os corpos negros são corpos humanos - torna visível e nomeia sua face encoberta e desumana: a branquitude.

Ao nomear os corpos brancos, a Negritude expõe a racialização como processo, a desnaturaliza, faz “[...] oposição ao segredo, à deformação e às representações mistificadoras impostas às pessoas" (FOUCAULT, 1995, p. 235). Pode-se fazer uma analogia à observação de Foucault (1977) sobre os movimentos feministas, que, segundo o filósofo, não negam o dispositivo da sexualidade, mas operam dentro dele para chegar a

[...] uma verdadeira dessexualização, enfim... a um deslocamento em relação à centralização sexual do problema, para reivindicar formas de cultura, discurso, linguagem, que não são mais esse tipo de atribuição e de fixação ao sexo que de alguma forma tiveram que aceitar politicamente para se fazer ouvir.14 (FOUCAULT, 1977, p. 16, tradução minha)

Assim, também, a resistência à racialização não parte de negar a racialização, mas de torná-la evidente, revelar seu segredo, seus mitos (FOUCAULT, 1995). Nas palavras de Moore (2010, p.19, grifo do original): "Raça existia; era uma construção social concreta [...] [h] avia que desmistificá-la e torná-la inoperante mediante um pensamento e uma práxis".

\footnotetext{
${ }^{10}$ Movimento cujas origens podem ser buscadas tanto nas lutas de independência de países africanos e americanos quanto nas lutas antirracistas da diáspora africana nas Américas (MOORE, 2010) e do qual pode-se, inclusive, buscar traços germinais nas lutas abolicionistas da diáspora, mesmo no Brasil, nos escritos de Luís Gama (DOMINGUES, 2005), por exemplo.

${ }^{11}$ Moore, ao abordar a afirmação da necessidade de enfrentamento ao racismo em Fanon, afirma: "A resistência ao racismo eleva o sujeito colonizado ao lugar de protagonista, devolvendo-lhe, com isso, a humanidade." (MOORE, 2010, p. 25, grifo do autor).

${ }^{12}$ Moore (2010) localiza os primeiros discursos da Negritude na obra de Aimé Césaire, Léopold Sédar Senghor e Leon Gontran Damas.

${ }^{13}$ Como na elaboração de leis que delimitam acesso a bens, terras, educação etc.

14 "À une véritable désexualisation, enfin... à un déplacement par rapport à la centration sexuelle du problème, pour revendiquer des formes de culture, de discours, de langage, qui ne sont plus cette espèce d'assignation et d'épinglage à leur sexe qu'elles avaient en quelque sorte politiquement bien dû accepter pour se faire entendre” (FOUCAULT, 1977, p. 16).
} 
Pioneiro nas pesquisas sobre o branco brasileiro, o sociólogo Guerreiro Ramos (1957) identificou o que ele nomeou "patologia social do branco brasileiro": afirmar uma branquitude que só é reconhecida no Brasil e negar qualquer origem ou influência negra ou indígena. A negação das origens negras também foi estudada por Lélia Gonzalez (1979, 1980, 1981a, 1981b, 1981c, 1985, dentre outros) em diversos textos em que, a partir das figuras da mucama - que se desdobra na da mulata e na da doméstica contemporâneas - e da mãe negra, assim como da avaliação de estatísticas sociais, a autora analisou, dentre outros temas, os processos de subjetivação do branco brasileiro por meio da constituição do negro e da negra como "outro".

Ao questionar o sujeito branco sobre o que é ser branco, Schucman (2012) recebeu como respostas variações sobre as posições de privilégio que os diversos indivíduos entrevistados ocupam: do mendigo à socialite, todos definiram o ser branco como uma posição de vantagem em relação aos sujeitos não brancos. Trata-se justamente da primeira dentre oito características da branquitude assinaladas por Ruth Frankenberg: "A branquidade ${ }^{15}$ é um lugar de vantagem estrutural nas sociedades estruturadas na dominação racial” (FRANKENBERG, 2004, p. 312).

A percepção dessa posição de vantagem, desse privilégio, marcou os Estudos Críticos da Branquitude desde seu início, antes mesmo de haver uma sistematização ou uma nomeação desse campo. Atribui-se a W.E.B. DuBois a realização de uma das primeiras análises publicadas que tomou o branco como objeto: em 1935, em Black Reconstruction in America, o autor observa de que maneira aderir à branquitude trouxe privilégios a imigrantes europeus poloneses, irlandeses e judeus - que, até organizarem-se em sindicatos que os separavam dos trabalhadores negros, não eram considerados brancos por não serem WASP ${ }^{16}$. DuBois é considerado autor de uma obra "incontornável na perspectiva dos fundamentos teóricos basilares do Panafricanismo e da Negritude" (MOORE, 2010, p. 10, grifos do autor).

Pensar o branco - nomeá-lo, colocá-lo como uma categoria racial a ser debatida - colabora com o estabelecimento de novos regimes de verdade e questiona os privilégios indisputados da branquitude. A branquitude tem sido caracterizada enquanto lugar de privilégios, que são fruto do dispositivo da racialidade que, sob a égide do regime de verdade racista, não nomeia o sujeito branco, portanto a branquitude, uma vez que esse lugar é percebido por esse discurso como lugar da neutralidade (BENTO, 2014); o sujeito branco não nomeado é o sujeito cartesiano, um sujeito sem corpo, percebido como neutro e universal (GROSFOGUEL, 2016). Tal gesto de denúncia da branquitude instaura, mais tarde, com a proliferação e o acúmulo de discursos produzidos, o que atualmente nomeamos "Estudos Críticos da Branquitude", um campo que, no Brasil, se organiza principalmente a partir dos anos 1990 (CARONE, 2014).

No âmbito desses estudos, a antropóloga afro-americana France Winddance Twine (TWINE, 2004 apud TWINE; STEINBUGLER, 2006) propõe o conceito de Racial Literacy ou letramento racial, que abarca práticas que visam à compreensão da maneira como a raça opera na sociedade e à desnaturalização da racialização e de suas consequências com o objetivo final de produzir equidade racial. A percepção de letramento racial como uma prática de leitura do mundo conversa com a definição de Aimé Césaire para Negritude: "[...] uma maneira de viver a história dentro da história" (CÉSAIRE, 2010, p. 109). A seguir, abordaremos especificamente esse conceito e o relacionaremos às técnicas de si.

\section{LETRAMENTO RACIAL E TÉCNICAS DE SI}

Em texto intitulado Sujeitos foucaultianos, Butler (2017) explica de que maneira os regimes de verdade influenciam sem, no entanto, determinar as formas de ser: o regime de verdade fornece os termos que possibilitam a produção de uma resposta à questão "quem sou eu", tais termos são "normas disponíveis pelas quais o reconhecimento de si acontece", essas normas constituem "o quadro e o

\footnotetext{
${ }^{15}$ Segundo o pesquisador Marcus Vinicius de Freitas Rosa (Informação verbal. Aula proferida pelo prof. dr. Marcus Vinicius de Freitas Rosa no Curso de Extensão Relações Raciais e Branquitude no Brasil, UFRGS, em 12 mai. 2021), esse termo, embora tenha sido usado na primeira leva de traduções de "whiteness" para o português brasileiro, tem caído em desuso em favor do termo "branquitude".
}

${ }^{16}$ White Anglo-Saxon Protestants: brancos, anglo-saxões protestantes - a classe que, historicamente, dominou a política e a economia norte-americanas. 
ponto de referência para quaisquer decisões que venhamos a tomar” sem que, no entanto, nossas decisões sejam determinadas por elas. Além das normas, "qualquer relação com o regime de verdade será ao mesmo tempo uma relação comigo mesma” (BUTLER, 2017, p. 35). Assim, compreende-se que o regime de verdade vinculado ao poder fornece coordenadas para a produção de sujeitos que responde, de diferentes maneiras, às normas estabelecidas.

Por outro lado, "[p]ôr em questão um regime de verdade, quando é o regime que governa a subjetivação, é pôr em questão a verdade de mim mesma e, com efeito, minha capacidade de dizer a verdade sobre mim mesma, de fazer um relato sobre mim mesma" (BUTLER, 2017, p. 35), o que significa que os processos de subjetivação ecoarão esses questionamentos. Uma relação crítica com o poder dá margem à criação de outros regimes de verdade que o questionam: "A crítica não diz respeito apenas $a$ uma prática social determinada ou a certo horizonte de inteligibilidade em que surgem as práticas e instituições; ela também significa que sou questionada em mim mesma" (BUTLER, 2017, p. 35s). A Negritude, enquanto produtora de uma crítica ao regime de verdade racista, tensiona os processos de subjetivação. Se, por um lado, o regime de verdade proposto pela Negritude não nega a racialização, por outro, essa racialização se dá em novos termos. Assim, temos uma alteração no processo de subjetivação em relação ao regime de verdade racista, orientada pelos regimes de verdade que emergem da crítica: o regime de verdade da Negritude, que reinstaura a humanidade dos sujeitos negros; o regime de verdade proposto pelo olhar dos Estudos Críticos da Branquitude, que questiona a positividade e os privilégios atribuídos aos sujeitos brancos. Nesse contexto, o letramento racial surge como um conjunto de práticas que, ao questionar aquilo que o regime de verdade racista propõe, produz novos sujeitos.

Como um conjunto de práticas que visa a uma transformação, uma nova produção de si, o letramento racial pode ser lido como "técnicas de si" (FOUCAULT, 2014). Com o objetivo de "[...] esboçar uma história das diferentes maneiras nas quais os homens, em nossa cultura, elaboram um saber sobre eles mesmos", Foucault (2014, p.265) se propõe a "[...] analisar essas pretensas ciências [que elaboram o saber do homem sobre ele mesmo] como outros tantos 'jogos de verdade’, que são colocadas como técnicas específicas dos quais os homens se utilizam para compreenderem aquilo que são”. Assim, são nomeados quatro grupos de técnicas específicas, dentre os quais, o quarto é o que nos interessa:

[A]s técnicas de si, que permitem aos indivíduos efetuarem, sozinhos ou com a ajuda de outros, um certo número de operações sobre seus corpos e suas almas, seus pensamentos, suas condutas, seus modos de ser; de transformarem-se a fim de atender um certo estado de felicidade, de pureza, de sabedoria, de perfeição ou de imortalidade. (FOUCAULT, 2014, p. 266)

No percurso de desenvolvimento das técnicas de si traçado por Foucault, desde os gregos ao cristianismo com menção aos reflexos na contemporaneidade, o cuidado de si surge como prática radicalmente reflexiva, uma relação do si consigo que, ainda que examine hábitos ligados ao corpo como a alimentação e a prática de exercícios físicos, se interessa prioritariamente pela alma - enquanto princípio do ser. Mais tarde, com os estoicos, as práticas de si tomam uma direção menos introspectiva no sentido de que se voltam para fora da alma, para os saberes dos mestres. Se "[p]ara Platão o indivíduo deve descobrir a verdade que se esconde nele" agora, "a verdade não está para ser descoberta no indivíduo, mas nos logoi, os preceitos dos mestres”. Dessa forma, a aprendizagem deve ser convertida "em regras de conduta. O objetivo dessas técnicas é a subjetivação da verdade." (FOUCAULT, 2014, p. 281, itálicos do original). Por meio da askêsis, os indivíduos buscam a transformação de si:

Na tradição filosófica inaugurada pelo estoicismo, a askêsis, longe de indicar a renúncia a si mesmo, implica na consideração progressiva de si, a maestria de si - uma maestria à qual se alcança não pela renúncia à realidade, mas ao se obter e assimilar a verdade. O objetivo final da askêsis não é preparar o indivíduo para uma outra realidade, mas de lhe permitir acessar a realidade deste mundo. (FOUCAULT, 2014, p. 281, itálicos do original, negritos meus)

O discurso da Negritude produz um novo regime de verdade sobre a raça, que nega a verdade racista e se coloca como mais verdadeiro, uma vez que busca, por meio dos discursos histórico e científico, "[A]cessar a realidade deste mundo", uma realidade que seria deturpada pela visão racista. O letramento racial, como prática de si, propõe uma relação com essa verdade que seja capaz de transformar a perspectiva dos indivíduos e produzir sujeitos que percebam a racialização que os produz. 
A descrição que Twine e Steinbugler (2006) nos oferecem de letramento racial como "um conjunto de práticas" que "[p]ode ser melhor caracterizado como uma 'prática de leitura' - uma maneira de perceber e responder ao ambiente racial e às estruturas raciais que o indivíduo encontra" (TWINE; STEINBUGLER, 2006, p. 344 ${ }^{17}$ ) pode ser relacionada à descrição foucaultiana de askêsis: "[a] askêsis é um conjunto de práticas pelas quais o indivíduo pode obter, assimilar a verdade, e transformá-la em um princípio de ação permanente" (FOUCAULT, 2014, p. 282, itálicos do original, negritos meus). Além disso, ao analisarmos os critérios definidos por Twine e Steinbugler (2006) para avaliar a presença do letramento racial, perceberemos que as ações descritas estão fortemente ligadas a "assimilar a verdade, e transformá-la em um princípio de ação permanente":

1) um reconhecimento do valor simbólico e material da Branquitude; 2) a definição do racismo como um problema social atual; 3) uma compreensão de que as identidades raciais são aprendidas e resultado de práticas sociais; 4) a posse de uma gramática e de um vocabulário racial que facilitem a discussão de raça, racismo e antirracismo; 5) a habilidade de traduzir (interpretar) os códigos e as práticas racializadas da nossa sociedade; e 6) uma análise das maneiras como o racismo é mediado por desigualdades de classe, hierarquias de gênero e pela heteronormatividade. (TWINE; STEINBUGLER, 2006, p. 344) (18 $^{18}$

"Reconhecimento", "compreensão", "habilidade de traduzir (interpretar)": atividades que apontam para o acesso do indivíduo a uma realidade que não está dada na superfície, mas que precisaria ser buscada, reconhecida, compreendida e traduzida - essa realidade que precisa ser acessada pode ser relacionada àquilo que Foucault nomeia "um certo estado de felicidade, de pureza, de sabedoria, de perfeição ou de imortalidade", especificamente, se pensarmos "sabedoria" e "perfeição" como um conhecimento sobre o jogo de racialização que está em vigor e uma conduta de acordo com esse conhecimento, respectivamente. Embora o vocabulário das estudiosas do letramento racial sinalize uma relação com a verdade como algo dado, pode-se perceber que, ao exercitar tais práticas, o indivíduo adere a um regime de verdade que já o interpela em sujeito racializado letrado. A diferenciação entre sujeito racializado - todo sujeito produzido pelo dispositivo da racialidade - e sujeito racializado letrado - o sujeito produzido a partir das práticas de si do letramento racial, que presumem adesão a um regime de verdade crítico ao regime de verdade racista - permite-nos observar as subjetivações enquanto processos de produção dos sujeitos por esses discursos já em relação com os regimes de verdade.

É preciso assinalar aqui o distanciamento entre o que nomeio "sujeito racializado letrado" e o sujeito da "branquitude crítica" pensada por Cardoso (2010). Enquanto os conceitos de branquitude crítica e branquitude acrítica remetem a duas posições estanques, a ideia de letramento racial indica processos de produção de sujeitos que, como tal, são dinâmicos, relacionais e nunca acabados. Além disso, há outro deslocamento, uma vez que o sujeito produzido pelas práticas de si do letramento racial não é apenas o sujeito da branquitude, mas qualquer sujeito produzido por um regime de verdade crítico ao regime de verdade racista. Em outras palavras, se o dispositivo racial produz sujeitos brancos e não brancos, os sujeitos produzidos pelas práticas de si do letramento racial podem ser tanto sujeitos brancos letrados quanto sujeitos não brancos letrados.

O sujeito produzido no exercício das práticas de si do letramento racial possui códigos, gramática, vocabulário e é proficiente a ponto de conseguir analisar não apenas o racismo, mas sua interação com outras formas de opressão, ou seja, o sujeito produzido por esse discurso é um sujeito com ferramentas para examinar sua própria produção enquanto sujeito racializado e possui uma espécie de metalinguagem para abordar o dispositivo da racialidade.

17 " $[\ldots]$ is a set of practices. It can best be characterized as a "reading practice" - a way of perceiving and responding to the racial climate and racial structures individuals encounter."

${ }^{18}$ Não há tradução brasileira desse trabalho, assim, todas as traduções que utilizo são minhas. No original: "1) a recognition of the symbolic and material value of Whiteness; 2) the definition of racism as a current social problem rather than a historical legacy; 3) an understanding that racial identities are learned and an outcome of social practices; 4) the possession of racial grammar and a vocabulary that facilitates a discussion of race, racism, and antiracism; 5) the ability to translate (interpret) racial codes and racialized practices; and 6) an analysis of the ways that racism is mediated by class inequalities, gender hierarchies, and heteronormativity. "(TWINE; STEINBUGLER, 2006, p. 344). 
O letramento racial corresponde a um processo, a um exercício de aprendizagem, “[...] uma prática cotidiana - uma postura analítica que facilita a autoeducação contínua" (TWINE; STEINBUGLER, 2006, p. 344) ${ }^{19}$, assim como a askêsis, que "[...] compreende um certo número de exercícios, nos quais o sujeito se coloca na situação de verificar se é capaz ou não de fazer face aos acontecimentos e de utilizar o discurso do qual está armado" (FOUCAULT, 2014, p. 282); ambos têm a finalidade de produzir uma conduta, uma postura crítica capaz de traduzir, decifrar e administrar a realidade (racial, no caso do letramento) orientando-se por uma verdade que deve se converter em ética, em atitude cotidiana.

Talvez seja prudente ressaltar que o letramento racial não é uma doutrina, mas o resultado de práticas cuja origem se encontra no olhar crítico que os discursos da Negritude e, consequentemente, dos Estudos Críticos da Branquitude, propõem. De acordo com Twine e Steinbugler, "[...] letramento racial representa uma postura analítica crítica desenvolvida em práticas microculturais cotidianas” (TWINE; STEINBUGLER, 2006, p. 357) ${ }^{20}$. A adesão a essas práticas provoca um deslocamento em relação ao discurso racista, afetando o processo de subjetivação: o sujeito negro se descola do que DuBois (2021 [1903]) chamou de dupla consciência - vê-se não pelo olhar racista, mas, por um olhar impregnado dos sentidos da negritude - enquanto o sujeito branco que se produz é dotado dessa dupla consciência como uma proficiência, uma competência para perceber e analisar o dispositivo da racialidade.

Dessa forma, uma vez que tais práticas transformam o si e influenciam a produção dos sujeitos, me parece coerente caracterizá-las como técnicas de si, no sentido foucaultiano dessa expressão. Tomar as práticas do letramento racial como técnicas de si evidencia, por exemplo, a intencionalidade necessária para que sejam exercidas. Twine e Steinbugler (2006), ao estudarem famílias inter-raciais observam que é a intimidade com sujeitos negros e a localização física e emocional em suas vidas que desencadeiam esses processos. No entanto, essa intimidade não é nem necessária nem suficiente: na pesquisa referida, as autoras apresentam casos de pessoas brancas que adquiriram o letramento racial e de pessoas brancas que não o adquiriram, sendo que o último grupo representa $75 \%$ do total. Schucman (2012) identificou, dentre quatorze entrevistados listados (SCHUCMAN, 2012, p. 42-43), apenas três que teriam desenvolvido letramento racial.

As autoras ressaltam, ainda, que tais práticas não são exclusividade de pessoas em famílias ou relacionamentos inter-raciais. O sujeito do processo de letramento racial, branco ou não, percebe a racialidade de outra maneira, a partir de outro regime de verdade. Tratase, no entanto, de um processo contínuo, em que o indivíduo desenvolve e aplica as técnicas de si em um exercício diário, sem nunca chegar a um final.

Tanto os estudos de Twine e Steinbugler (2006) quanto de Schucman (2012) mencionam a relevância fundamental da relação com o outro nesse processo. A partir de um ponto de vista enunciativo, dizemos que o sujeito se constitui e se apresenta linguisticamente, mas não apenas, na intersubjetividade, na reciprocidade da troca de papéis de eu e tu na língua (BENVENISTE, 2005a [1956], 2005b [1958]). Se, no pensamento benvenisteano, a subjetividade se constitui na intersubjetividade, na cena eu-tu/ele, Silva (2009), ao estudar a aquisição da linguagem pelas crianças, chama a atenção para o papel primordial da cultura em que os sujeitos estão inseridos na aprendizagem da língua - que se dá sempre incontornavelmente relacionada à aprendizagem da cultura. Para essa autora, a cena enunciativa abarca uma outra instância, um Ele, com inicial maiúscula, que representa a onipresença da cultura nas interações humanas, na produção de sujeitos. Assim, o "eu-tu/ele" benvenisteano torna-se eu-tu/ele/Ele. Cultura diz respeito à realidade em que os indivíduos estão inseridos, portanto, aos dispositivos que produzem os sujeitos e aos regimes de verdade que regem tais produções. A poética afirmação benvenisteana talvez resuma bem: "[...] o homem não nasce na natureza, mas na cultura” (BENVENISTE, 2006 [1968], p. 23). Assim como na askêsis, os exercícios partem de um conhecimento que se adquire de um outro, alguém mais experiente: para os estoicos, essa figura é a do mestre, já no letramento racial, pode se tratar de um familiar ou parceira/o romântico (TWINE; STEINBUGLER, 2006), de um amigo ou colega de trabalho ou até de um eu lírico a que se tem acesso pela música, por exemplo (SCHUCMAN, 2012).

\footnotetext{
19 "Racial literacy is an everyday practice - an analytic stance that facilitates ongoing self-education and enables members of interracial families to translate racial codes, decipher racial structures, and manage the racial climate in their local and national communities".
}

20 "We have argued that racial literacy represents a critical analytic stance developed through everyday microcultural practices". 
Twine e Steinbugler (2006) reconhecem três práticas ${ }^{21}$ desenvolvidas pelos indivíduos brancos para atingir as competências e atitudes listadas: desenvolvimento da dupla visão - que as autoras desenvolvem a partir do conceito de dupla consciência de DuBois ([1903] 2021) 22; negociação dos sentidos localizados de branquitude; e percepção de ocorrências rotineiras de racismo cotidiano ${ }^{23}$. Schucman (2012) identifica que os indivíduos brancos que desenvolvem letramento racial são aqueles que estabelecem relações não hierarquizadas com indivíduos não brancos. A partir dessas relações, são exercidas técnicas de si que produzem sujeitos brancos que se sabem brancos, que entendem o que isso acarreta socialmente para eles e que efetuam "[...] um certo número de operações sobre seus corpos e suas almas, seus pensamentos, suas condutas, seus modos de ser [...]" (FOUCAULT, 2014, p. 266).

Assim, pode-se perceber que as práticas que levam ao letramento racial são exercícios rotineiros que alteram a relação do indivíduo com os regimes de verdade produzindo sujeitos que exercem um domínio de si em relação ao dispositivo da racialidade: não aceitam simplesmente as categoriais criadas por esse dispositivo como naturais; por meio da "sabedoria" proporcionada pela prática desses exercícios, isto é, do letramento racial, percebem a racialização de forma crítica.

\section{CONSIDERAÇÕES FINAIS}

As práticas de letramento racial são reflexos de uma mudança na dinâmica dos regimes de verdade atuantes no dispositivo racial. Tais mudanças remetem à produção de discursos no âmbito do movimento da Negritude em sua forma ampla, abarcando desde a revolta haitiana - segundo Césaire (2010) - até cada gesto de autodefinição dos sujeitos negros contemporâneos. Os Estudos Críticos da Branquitude se constituem como resultado dessa dinâmica, que leva o branco a ser considerado na questão das relações raciais.

O caráter contínuo e iterativo das técnicas de si do letramento racial está intimamente relacionado à maneira como o dispositivo da racialidade atualiza cotidianamente a cena colonial (KILOMBA, 2019) revitalizando o regime de verdade racista que, consequentemente, é colocado em tensão com os regimes de verdade que o questionam, que a ele oferecem resistência. Esse sujeito, sempre processo, sempre se produzindo, é efeito de práticas que se colocam em ação a partir da relação entre o si - o eu - e o outro. Tal relação pode ser configurada no modelo linguístico benvenisteano (BENVENISTE, 2005a [1956], 2005b [1958]) do eu, do tu (pessoas) e do ele (não pessoa): enquanto o sujeito racializado como não branco ocupa o lugar do ele, está fora da relação de intersubjetividade, está coisificado. Uma vez que esse sujeito ocupa o lugar do eu - não pela tomada natural de turno de que um $t u$ poderia se valer, mas de assalto, exigindo o turno e constituindo-se como $e u$ à força de resistência - aquele $e u$ que não o estabelecia como tu é interpelado e precisa se reconfigurar. A cena enunciativa se abala, é alterada de forma que não pode mais retornar ao estado anterior. O regime de verdade racista é confrontado com outros regimes de verdade e a agonística que daí emerge produz novos sujeitos, em processo de letramento racial.

No entanto, não é sempre que o eu antigo se deixa interpelar pelo novo, isto é, não é sempre que o eu antigo se coloca no lugar de tu que o ele-tornado-eu o indica. Nesses casos - que, como vimos em Twine e Steinbugler (2006) e em Schucman (2012), podem ser maioria - o eu antigo não aceita a interlocução com o ele-tornado-eu, não aceita seu lugar de tu e nada novo se produz: não há letramento, não há produção de um novo sujeito letrado. Contudo, mesmo que as técnicas de si do letramento racial não estejam amplamente disseminadas, o dispositivo racial não retorna a seu estado anterior, foi modificado e está marcado pela luta entre as forças que se opõem em seu interior.

${ }^{21}$ Abordaremos essas práticas em mais detalhes a seguir.

${ }^{22}$ Uma explicação cabe aqui: para DuBois, a dupla consciência era uma atribuição das pessoas racializadas como negras: "É uma sensação peculiar, essa consciência dual, essa experiência de sempre enxergar a si mesmo pelos olhos dos outros [...]. O indivíduo sente sua dualidade - é um norte-americano e um negro” (DUBOIS, [1903] 2021, p. 23), já, para Twine e Steinbugler, a dupla visão pode ser desenvolvida por qualquer pessoa como parte de seu processo de letramento racial.

${ }^{23}$ Uma vez que as autoras não oferecem, nesse texto, um conceito de racismo cotidiano, nos valemos do conceito como o propõe Grada Kilomba: "O racismo cotidiano refere-se a todo vocabulário, discursos, imagens, gestos, ações e olhares que colocam o sujeito negro e as Pessoas de Cor não só como "Outra/o" - a diferença contra a qual o sujeito branco é medido - mas também como Outridade, isto é, como a personificação dos aspectos reprimidos na sociedade branca.” (KILOMBA, 2019, p. 78). 


\section{REFERÊNCIAS}

BENTO, M. A. S. Branqueamento e branquitude no Brasil. In: CARONE, I.; BENTO, M. A. S. (org.). Psicologia social do racismo. 6. ed. Petropólis: Vozes, 2014. p. 25-58.

BENVENISTE, É. A natureza dos pronomes. [1956]. In: BENVENISTE, É. Problemas de lingüística geral I. Campinas: Pontes, 2005a. p. $277-283$.

BENVENISTE, É. Da subjetividade na linguagem. [1958]. In: BENVENISTE, É. Problemas de lingüística geral I. Campinas: Pontes, 2005b. p. 284-293.

BENVENISTE, É. Estruturalismo e linguística. [1968]. In: BENVENISTE, É. Problemas de lingüística geral II. Campinas: Pontes, 2006. p.11-28.

BUTLER, J. Relatar a si mesmo: crítica da violência ética. Belo Horizonte: Autêntica, 2017.

CARNEIRO, A. S. A construção do outro como não-ser como fundamento do ser. 2005. 339 f. Tese (Doutorado) - Programa de PósGraduação em Educação, Educação, Universidade de São Paulo, São Paulo, 2005. Disponível em: https://negrasoulblog.files.wordpress.com/2016/04/a-construc3a7c3a3o-do-outro-como-nc3a3o-ser-como-fundamento-do-sersueli-carneiro-tese1.pdf. Acesso em: 19 mar. 2021.

CARONE, I. Breve histórico de uma pesquisa psicossocial sobre a questão racial brasileira”. In: CARONE, I.; BENTO, M. A. S. (org.). Psicologia social do racismo. 6. ed. Petropólis: Vozes, 2014. p. 13-24.

CARVALHO, E.; SCHWARCZ, L.. PodEntrar: entrevista de Lilia Schwarcz a Eduardo Carvalho. Instagram @educarvalhol, 3 ago. 2020. Disponível em: .https://www.instagram.com/p/CDcXH61pgVZ. Acesso em: 24 abr. 2021.

CARDOSO, C. P. Amefricanizando o feminismo: o pensamento de Lélia Gonzalez. Revista Estudos Feministas, Florianópolis, v. 22, n. 3, p. 965-986, set./dez. 2014. Quadrimestral. Disponível em: https://periodicos.ufsc.br/index.php/ref/article/view/36757. Acesso em: 12 jul. 2021.

CARDOSO, L. Branquitude acrítica e crítica: A supremacia racial e o branco anti-racista. Revista Latinoamericana de Ciencias Sociales, Niñez y Juventud. jan. 2010, v.8, n.1, p. 607-630. Disponível em: http://www.scielo.org.co/scielo.php?script=sci arttext\&pid=S1692-715X2010000100028\&lng=pt\&nrm=iso. Acesso em: 3 maio 2021.

CÉSAIRE, A. Discurso sobre a Negritude. Belo Horizonte: Nandyala, 2010.

CÉSAIRE, A. Discurso sobre o colonialismo. São Paulo: Veneta, 2020

DA MATTA, R. Notas sobre o racismo à brasileira. In: SOUZA, J. (org.) Multiculturalismo e racismo. Brasília: Paralelo 15, 1997. p.13-21.

DOMINGUES, P. Movimento da Negritude: uma breve reconstrução histórica. Mediações: Revista de Ciências Sociais, Londrina, v. 10, n. 1, p. 25-40, jan./jun. 2005.

DUBOIS, W. E. B. As almas do povo negro. São Paulo: Veneta, 2021 [1903].

DUBOIS, W. E. B. Black reconstruction in America. [1935] London: Transaction Publishers, 2013

Forum lingüístic., Florianópolis, v. 18,n. 3, p.6400-6415, jul./set.2021. 
FANON, F. Peles negras, máscaras brancas. São Paulo: Ubu, 2020.

FOUCAULT, M. As técnicas de si. In: FOUCAULT, M. Ditos e escritos: IX. Rio de Janeiro: Forense Universitária, 2014. p. $264-296$.

FOUCAULT, M. A história da sexualidade 1: a vontade de saber. São Paulo: Graal, 2006.

FOUCAULT, M. Nietzsche, a genealogia e a história. In: FOUCAULT, M. Microfísica do poder. Rio de Janeiro: Graal, 1998. p.15-37.

FOUCAULT, M. O sujeito e o poder. In: DREYFUS, D.; RABINOW, P. Michel Foucault: uma trajetória filosófica. Rio de Janeiro: Forense Universitária, 1995. p.231-249.

FOUCAULT, M. Genealogia del racismo. Buenos Aires: Allamira, 1993.

FOUCAULT, M. Le jeu de Foucault. [Entrevista concedida a COLAS, D.; GROSRICHARD, A.; LE GAUFEY,G.; LIVI, J.; MILLER, G.; MILLER, J.; MILLER, J.-A.; MILLOT, A.; WAJEMAN, G. Bulletin Périodique du champ freudien, n. 10, p. 62-93, jul. 1977.

FRANKENBERG, R. A miragem de uma branquidade não-marcada. In: WARE, V. (org.). Branquidade: identidade branca e multiculturalismo. Rio de Janeiro: Garamond Universitária; Centro de Estudos Afro-Brasileiros, 2004. p. 307-338.

FRY, P. O que a cinderela negra tem a dizer sobre a "política racial” no Brasil. Revista USP, n. 28, p. 122-135, 1995-1996.

GONZALEZ, L. Cultura, etnicidade e trabalho. In: GONZALEZ, L. Primavera para as rosas negras. São Paulo: União dos Coletivos Pan-Africanistas, 2018 [1979]. p. 54-76.

GONZALEZ, L. Racismo e sexismo na cultura brasileira. In: GONZALEZ, L. Primavera para as rosas negras. São Paulo: União dos Coletivos Pan-Africanistas, 2018 [1980]. p. 103-108.

GONZALEZ, L. A mulher negra na sociedade brasileira. In: GONZALEZ, L. Primavera para as rosas negras. São Paulo: União dos Coletivos Pan-Africanistas, 2018 [1981a]. p. 34-53.

GONZALEZ, L. Mulher negra. In: GONZALEZ, L. Primavera para as rosas negras. São Paulo: União dos Coletivos Pan-Africanistas, 2018 [1981b]. p.103-108.

GONZALEZ, L. Democracia racial? Nada disso! In: GONZALEZ, L. Primavera para as rosas ne.gras. São Paulo: União dos Coletivos Pan-Africanistas, 2018 [1981c].p. 109-111.

GONZALEZ, L. A democracia racial: uma militância. In: GONZALEZ, L. Primavera para as rosas negras. São Paulo: União dos Coletivos Pan-Africanistas, 2018 [1985]. p. 255-257.

GROSFOGUEL, R. A estrutura do conhecimento nas universidades ocidentalizadas: racismo/sexismo epistêmico e os quatro genocídios/epistemicídios do longo século XVI. Sociedade e Estado, Brasília, v. 31, n. 1, p. 25-49, jan. 2016. 
HAMILTON Mourão diz que não existe racismo no Brasil. Deutsche Welle. [on-line]. nov. 2020. Disponível em: https://p.dw.com/p/3ldRN. Acesso em: 4 maio 2021.

HOFBAUER, A. Branqueamento e democracia racial - sobre as entranhas do racismo no Brasil. In: ZANINI, M. C. C. (org.). Por que "raça"?: breves reflexões sobre a questão racial, no cinema e na antropologia. Santa Maria: Ed. UFSM, 2007. p.151-188.

GUERREIRO RAMOS, A. Patologia social do 'branco' brasileiro”. In: GUERREIRO RAMOS, A. Introdução crítica à sociologia brasileira. Rio de Janeiro: Editora UFRJ, 1957.

KILOMBA, G. Memórias da plantação: episódios de racismo cotidiano. Rio de Janeiro: Cobogó, 2019.

LUCCHESI, D. Ciência ou dogma? O caso do livro do MEC e o ensino de língua portuguesa no Brasil. Revista Letras, Curitiba, v. 83, p. 163-187, jun. 2011. Disponível em: https://revistas.ufpr.br/letras/article/view/24713. Acesso em: 19 maio 2021.

MAIO, M. C. O Projeto Unesco e a agenda das ciências sociais no Brasil dos anos 40 e 50. Rev. bras. Ci. Soc., São Paulo, v. 14, n. 41, p. 141-158, out. 1999. Disponível em http://www.scielo.br/scielo.php?script=sci arttext\&pid=S010269091999000300009\&lng=en\&nrm=iso. Acesso em: 4 maio 2021.

MBEMBE, A. Crítica da razão negra. Trad. Sebastião Nascimento. São Paulo: n-1 Edições, 2018.

MOORE, C. Racismo e sociedade. Belo Horizonte: Nandyala, 2012.

MOORE, C. Prefácio. In: CÉSAIRE, A. Discurso sobre a Negritude. Belo Horizonte: Nandyala, 2010. p.7-38.

MUNANGA, K. Uma abordagem conceitual das noções de raça, racismo, identidade e etnia. Palestra proferida no 3o Seminário Nacional Relações Raciais e Educação - PENESB-RJ, Rio de Janeiro, 2004. Disponível em: https://www.ufmg.br/inclusaosocial/?p=59. Acesso em: 20 fev. 2019.

RATTS, A.; RIOS, F. Lélia Gonzalez. São Paulo: Selo Negro, 2010. (Retratos do Brasil Negro).

SCHUCMAN, L. Entre o "encardido", o "branco" e o "branquíssimo": raça, hierarquia e poder na construção da branquitude paulistana. 2012. 100 f. Tese (Doutorado) -Curso de Psicologia Social, Instituto de Psicologia, Universidade de São Paulo, São Paulo, 2012.

SCHUCMAN, L. Aula: Branquitude e Estudos Críticos da Branquitude - Disciplina do Curso de Psicologia Social, Instituto de Psicologia, Universidade Federal de Santa Catarina, 2020.

SCHWARCZ, L. Nem preto nem branco muito pelo contrário: cor e raça na intimidade. São Paulo: Companhia das Letras, 2012.

SILVA, C. L. da C. A instauração da criança na linguagem: princípios para uma teoria enunciativa em aquisição da linguagem. 2007. 293 f. Tese (Doutorado) - PPG em Estudos da Linguagem, Universidade Federal do Rio Grande do Sul, Porto Alegre, 2007. Disponível em: http://hdl.handle.net/10183/10407. Acesso em: 20 mar. 2021.

SOVIK, L. Por que tenho razão: branquitude, estudos culturais e a vontade de verdade acadêmica. Contemporânea: Revista de Comunicação e Cultura, $\left[\begin{array}{ll}\mathrm{s} . & 1\end{array}\right], \quad$ v. $\quad 3, \quad$ n. $\quad 2, \quad$ p. $\quad 159-180, \quad 2005 . \quad$ Disponível em: https://www.academia.edu/1208769/Por que tenho raz\%C3\%A3o branquitude Estudos Culturais e a vontade de verdade acad\%C3\%AAmica. Acesso em: 18 maio 2021. 
TWINE, F. W.; STEINBUGLER, A. The gap between whites and whiteness: interracial intimacy and racial literacy. Du Bois Review: Social Science Research on Race, New York, v. 2, n. 3, p. 341-363, ago. 2006. Disponível em: https://www.researchgate.net/publication/231775543_The_gap_between_whites_and_whiteness_Interracial_Intimacy_and_Ra cial_Literacy. Acesso em: 26 mar. 2021.

VEYNE, P. Foucault: seu pensamento, sua pessoa. Rio de Janeiro: Civilização Brasileira, 2011.

\section{() (1) $\circledast$}

Recebido em 13/06/2021. Aceito em 12/07/2021. 